Revue de l'Institut des langues et cultures

d'Europe, Amérique, Afrique, Asie et Australie

$25 \mid 2016$

De la bibliothèque intérieure à la bibliothèque collective : livres et lectures en Espagne (XVI $\mathrm{I}^{\mathrm{e}} \mathrm{XX \textrm {I } ^ { \mathrm { e } }}$ siècles)

\title{
Libros y lecturas poéticas del Gobernador de Milán: épica vernácula en la biblioteca de Juan Fernández de Velasco, V duque de Frías
}

Livres et lectures poétiques du Gouverneur de Milan : poésie épique en langue moderne dans la bibliothèque de Juan Fernández de Velasco, $5^{e}$ duc de Frías The Books and Poetic Works of the Governor of the Duchy of Milan: The Vernacular Epic in the Library of Juan Fernández de Velasco, Fifth Duke of Frías Juan Montero y Pedro Rueda Ramírez

\section{(2) OpenEdition} Journals

Edición electrónica

URL: http://journals.openedition.org/ilcea/3687

DOI: 10.4000/ilcea.3687

ISSN: 2101-0609

Editor

UGA Éditions/Université Grenoble Alpes

Edición impresa

ISBN: 978-2-84310-322-3

ISSN: $1639-6073$

Referencia electrónica

Juan Montero y Pedro Rueda Ramírez, «Libros y lecturas poéticas del Gobernador de Milán: épica vernácula en la biblioteca de Juan Fernández de Velasco, V duque de Frías », ILCEA [En línea], 25 | 2016, Publicado el 31 enero 2016, consultado el 19 abril 2019. URL : http:// journals.openedition.org/ilcea/3687 ; DOI : 10.4000/ilcea.3687

Este documento fue generado automáticamente el 19 abril 2019.

(C) ILCEA 


\section{Libros y lecturas poéticas del Gobernador de Milán: épica vernácula en la biblioteca de Juan Fernández de Velasco, V duque de Frías}

Livres et lectures poétiques du Gouverneur de Milan : poésie épique en langue moderne dans la bibliothèque de Juan Fernández de Velasco, $5^{e}$ duc de Frías The Books and Poetic Works of the Governor of the Duchy of Milan: The Vernacular Epic in the Library of Juan Fernández de Velasco, Fifth Duke of Frías Juan Montero y Pedro Rueda Ramírez

\section{Juan Fernández de Velasco, condestable de Castilla}

1 Juan Fernández de Velasco y Tovar provenía de una familia aristocrática de alta alcurnia con una larga trayectoria de servicio a los monarcas castellanos. Las alianzas matrimoniales de la familia de los Condestables de Castilla en los siglos XV y XVI fueron consolidando un complejo entramado de títulos nobiliarios. Su padre fue el condestable Íñigo Fernández de Velasco (c. 1520-1585), que tuvo once hijos fruto de su matrimonio con Ana de Guzmán y Aragón (c. 1525-1589), hija del VI duque de Medina Sidonia, Juan Alonso Pérez de Guzmán. Juan Fernández de Velasco y Tovar (c. 1550-1613) fue el primogénito y recibió los títulos, entre otros, de V duque de Frías, VI condestable de Castilla y VII conde de Haro. La política familiar de fomentar los enlaces matrimoniales con otros miembros de la alta nobleza lo llevó a casarse dos veces, la primera en 1569, con María Girón de Guzmán (1553-1608), y la segunda en 1609 con Juana Fernández de Córdoba y Aragón (1586-1624) (Montero, González, Rueda \& Alonso, 2014). 
2 Fernández de Velasco destacó como militar y diplomático al servicio de Felipe II y Felipe III. En su larga carrera profesional desempeñó tareas de gestión de un enorme patrimonio familiar y cargos de confianza de la Corona. En 1592 fue nombrado gobernador de Milán y capitán general de Italia, en sustitución de Carlos de Aragón y Tagliavia (1530-1599), duque de Terranova. Allí permanecería hasta 1600, año en el que regresó a la Corte y, como premio a su gobierno en el estado lombardo, Felipe III lo designó miembro del Consejo real de Estado y de Guerra, además de presidente del Consejo Supremo de Italia. Si bien en 1610 el rey lo designó, de nuevo, para la gobernación del Milanesado, plaza que definitivamente abandonaría en 1612, unos meses antes de su fallecimiento, acaecido en 1613. Estas tareas en Italia influyeron, de manera esencial, en sus intereses y gustos lectores, ya que reunió una de las bibliotecas más selectas de fondos de procedencia italiana, además de una riquísima colección artística. Aunque los buenos libros y el estudio le interesaron desde joven, tal como destacaba su biógrafo Fermín López de Mendizorroz, que describía su infancia rodeado de libros, de los que «chupó la substançia de doctrina, y buena enseñanza, que a guisa de diestra abeja, anduvo forjando para sí un suavísimo panal de heroicas virtudes» (López de Mendizorroz, 1625: 2). A sus aficiones se sumaron sus constantes viajes como militar o diplomático, que le facilitaron un conocimiento del ambiente cultural de las cortes italianas e inglesa, como cuando acompañó a su suegro Pedro Téllez-Girón (1537-1590), I duque de Osuna, en su paso a Nápoles como virrey en 1582. En cierto modo siguió el modelo de numerosos príncipes italianos, hombres de letras y gobierno con intereses en la literatura, como el príncipe Leopoldo de Medici, que inició su carrera política como gobernador en Siena a la par que, con 21 años, iniciaba su colección con libros de historia y derecho (Mirto, 1990: 40-41). Una biblioteca con la que la del Condestable tenía algunas coincidencias; por ejemplo, ambos poseían la misma edición de los Discorsi politici de Paolo Paruta (Venecia, 1599) (Mirto, 1990: 380; Index auctorum, f. 170r).

3 El Condestable tuvo intereses tanto literarios como militares, aunando el ideal de las armas y las letras. Este aspecto puede apreciarse en las coincidencias entre su biblioteca y la de Rodrigo de Silva y Mendoza, II duque de Pastrana. Este joven noble, fallecido a los 33 años en Luxemburgo como consecuencia de heridas de guerra, contaba con una selecta biblioteca de 31 títulos que incluía tratados militares, textos de historia y política, libros devocionales y algunos títulos de literatura en castellano e italiano (Dadson, 1988: 152-154). Ambos nobles poseían los Comentarios de Julio César, De militia romana de Justo Lipsio y el Perfecto capitán de Diego de Alaba y Viamont, esta última obra en la misma edición de Madrid de 1590, que incluía un apartado de la «nueva ciencia de la artillería» que resultaría de gran interés en las campañas militares de ambos.

\section{La biblioteca del Condestable}

El estudio de 245 inventarios nobiliarios de Madrid de los años 1550 a 1650 revela que el $61,2 \%$ de los miembros de la nobleza poseían bibliotecas en la Corte. Las 150 bibliotecas nobiliarias analizadas por Prieto revelan que la media de títulos se situaba en torno a los 150. Tan sólo un grupo selecto poseía más de 500 títulos en sus casas en la Corte y sólo seis bibliotecas superaban los mil volúmenes. Entre estas se encontraban la del Condestable, con casi cuatro mil volúmenes, el marqués de Narros, Jerónimo de Eguía, con 2.469 libros, el marqués de Alcalá, con 1.861, el Almirante de Castilla, con 1.438, y el marqués de Vall, con 1.425 (Prieto Bernabé, 2004: II, 29; Torrego Casado, 2011: 106). En algunos casos los 
libros estaban en sus casas solariegas de origen, repartidos entre sus diferentes propiedades, pero poco a poco muchos de estos nobles al servicio del Rey se instalaron en Madrid de forma permanente, compraron terrenos y edificaron palacios que les permitieron reunir sus colecciones como muestra de prestigio del linaje y de su posición en el favor real. Este fue el caso del Condestable.

el estudio de esta biblioteca resulta esencial el Index auctorum, et librorum nomina, un índice de autores y obras conservado en la Biblioteca Nacional de España (ms. 7840). Se trata de una pieza clave para el mejor conocimiento del coleccionismo nobiliario en tiempos de Felipe II y Felipe III (Andrés, 1972: 219-228). El manuscrito 7840 formó parte de los volúmenes comprados al X duque de Frías, cuya adquisición se anotó en el Registro de la compra de libros para la Real Biblioteca como el: «Índice de la librería del condestable D. Juan Fernández de Velasco: fol. ms.», el 30 de diciembre de 1739 (Fernández Pomar, 1967: 93). El Index se corresponde con un sistema alfabético, siguiendo el sentido pragmático de recoger los autores y títulos. Cada letra del abecedario latino se divide en cuatro apartados por lengua, en primer lugar los «auctores latini», seguidos de los de «lingua italiana», a continuación «in lengua francesa»y, finalmente, «en lengua española», que incluye textos en castellano, catalán y portugués. El índice servía para controlar los volúmenes adquiridos, pero también era un inventario de los libros reunidos por la familia.

6 Además de este catálogo de autores, que suele fecharse en torno a 1600, contamos con dos inventarios notariales de los bienes de la familia Velasco. El primero de 1608, realizado a raíz de la muerte de su primera esposa María Girón de Guzmán, prima hermana suya e hija de Pedro Téllez Girón, I duque de Osuna (Archivo Histórico de Protocolos de Madrid (AHPM), leg. 24850). El óbito en 1607 de su hijo Íñigo, su primogénito, le llevó a contraer nuevas nupcias, por ello acometió el inventario y tasación de su fortuna, para distinguir la parte de doña María. Al poco tiempo se casó con doña Juana de Córdoba y Aragón, que al año siguiente le daría un hijo, Bernardino Fernández de Velasco, que sería el heredero de los títulos y continuador de la biblioteca de los Velasco. El segundo inventario notarial, de 1613, se hizo tras su fallecimiento, cumpliendo lo referente a herencias y reparto de propiedades. La biblioteca aparece detallada únicamente en el primero de los inventarios. Esto es debido a que en las disposiciones testamentarias de 1613 se indicaba «que esté siempre vinculada en el mayorazgo toda la librería que tengo», sin venderse ni dividirse, quedando de este modo en manos de su heredero, para que «los sucesores de mi casa tengan memoria y se acuerden que así como las dos cosas principales con que se adquiere la nobleza y se conserva son las armas y las letras» (Matilla Tascón, 1983: 120).

7 En el inventario de sus bienes realizado en 1608 el entallador Roque de Falque se encargó de tasar las maderas de la sala en la que estaban buena parte de los libros en la casa del Condestable en Madrid. Esto nos permite conocer la disposición de los libros en 64 cajones, con 32 asientos de nogal. Los cajones se organizaban en altos y bajos, «aforrados por de dentro de camuza [i.e. gamuza] pespuntada y por de fuera de baqueta colorado con sus aldabones y en las tapas unos mapas». En los 24 cajones altos de la biblioteca del Condestable se encontraban «los retratos de los auctores de los dichos libros» (AHPM, leg. 24850, f. 479v). El pintor Diego de Cuevas los tasó indicando que eran «cinquenta retratos que están en los caxones de los libros tassado cada uno a diez y seis reales» (AHPM, leg. 24850, f. 260r). La correlación entre los textos contenidos en cada cajón y los retratos puede corroborarse. En el número 1 alto (el primero de la serie y elevado) se incluían textos de la Biblia, de los Padres de la Iglesia y obras litúrgicas. En 
este caso la decoración «tiene a Moysés y a Sant Juan» (AHPM, leg. 24850, f. 269r), es decir, acorde a la temática, representa -y contrapone- un escritor del Antiguo Testamento, Moisés, con otro, San Juan Evangelista, del Nuevo Testamento. En ambos ejemplos hay otro aspecto que conviene resaltar, ya que se trata de dos mediadores de las Escrituras, uno judío y el otro cristiano. En el resto de cajones del inventario no se especifican las figuras representadas, pero el modelo analizado es un indicio de la más que probable ordenación par de los retratos para cada cajón alto, esto supone al menos 48 retratos para los 24 cajones superiores con una iconografía que debió seguir el esquema de las galerías de sabios de la Antigüedad y hombres ilustres por sus escritos, tan del gusto de la época (López Torrijos, 1998). El studiolo de Urbino de Federico de Montefeltro siguió estos principios, con 28 retratos que incluían a Moisés, Salomón, escritores clásicos (Cicerón, Séneca o Virgilio), Padres de la Iglesia, teólogos y humanistas como Petrarca (Fenucci \& Simonetta, 2007: 88-99). Además en la biblioteca del Condestable se encontraban algunos pequeños bronces, tenía más de cien en su colección, como un «caballejo enrizado» y un «torillo». Y guardaba, como era habitual entre aficionados a la Antigüedad, una rica colección de medallas (Montero, González, Rueda \& Alonso, 2014: 146-147).

También sabemos que se trajeron de Burgos para la librería 41 retratos que incluían una galería pictórica de la familia Velasco, donde figuraban los descendientes del linaje hasta llegar a Juan Fernández de Velasco (AHPM, leg. 24850, f. 250r). Los óleos familiares convertían la sala en un espacio idóneo para representar la relación de los saberes con los servicios a la Corona. En algunos palacios italianos las salas de libros se convirtieron en un modelo clave de los intereses lectores de las aristocracias con intereses políticos. El caso del palacio ducal de Mantua es revelador de esta voluntad de generar espacios idóneos para albergar las colecciones y dotar a los objetos de un contexto idealizado. En el «camerino della Fama» se albergaba una selecta biblioteca de 179 obras, con un entorno decorativo alegórico que reforzaba la gloria de los Gonzaga y su papel como promotores de las letras y el saber (Koering, 2013: 250-252). Este modelo mantuano era bien conocido por el Condestable, que visitó el palacio. Cofiño y Escudero (2008: 151-184) consideran, de hecho, que la serie genealógica encargada por Federico de Gonzaga para su librería de Mantua fue un posible modelo para la del Condestable.

El Condestable de Castilla también reunió libros en su camarín. Al igual que otros coleccionistas dedicó un notable esfuerzo e interés a los libros, atesorando los más adecuados a sus aficiones. Los textos podían amontonarse en pilas, acumularse al lado de la chimenea, sobre las mesas, en doble fila en los armarios y distribuidos por tamaños en los estantes, tal como sucedía con los libros de Naudé en el Catalogue des livres qui sont en l'estude de G. Naudé à Paris, que alcanzaba más de tres mil quinientas entradas, que incluían los libros del cabinet de uno de los bibliotecarios más célebres de la época (Bœuf, 2007). El studiolo o camarín se había constituido en el caso del Condestable en una biblioteca de uso y lectura, en la que podían encontrarse nuevos libros, textos dedicados al dueño o algunos de sus escritos. El camarín revela un microcosmos de la totalidad de la biblioteca, al dar buena cuenta de textos eruditos, con unos 635 impresos y 35 manuscritos. Entre ellos, obras recién publicadas de derecho civil, obras de historia romana, como las Inscriptiones antiquae totius orbis Romani de Janus Gruterus (1560-1627) y títulos raros, como la Segunda parte de la Cavalleria Celestial (Valencia, 1554) de Jerónimo de San Pedro, que aparecía como prohibido en los índices inquisitoriales españoles (Vílchez Díaz, 1986: 776). 


\section{La colección de poesía épica de la biblioteca}

10 Una de los rasgos que singulariza la biblioteca del Condestable es la destacada presencia que tiene en ella la literatura de creación, tanto poética como dramática, con particular preferencia por los clásicos greco-latinos y por los autores italianos y españoles contemporáneos. En las líneas que siguen, nos vamos a ocupar de un capítulo destacado de ese gusto literario, el constituido por la producción épica vernácula, en todas sus manifestaciones (Chevalier, 1976: 104-137; Cacho Casal, 2012). El hecho no tiene nada de sorprendente, por dos razones. En primer lugar, el enorme prestigio de un género que la teoría de la época situaba en la cúspide de la jerarquía literaria. En segundo lugar, su innegable atractivo para alguien que ostentaba la doble condición de noble y de gobernante. Como señala Vega:

Es común en la Europa altomoderna la convicción de que la lectura de hechos esforzados - de la historia, de la crónica y de la épica- tiene un valor ejemplar y enseña al príncipe a ser mejor príncipe, ya que la virtud llama a la virtud (2010: 123).

11 La cita viene a recordarnos que la épica (entendida en un sentido específico, por oposición a los romanzi y otras formas de poesía narrativa de tema heroico) se hermana con la historia en tanto que escrituras útiles para la educación del príncipe. Y, en efecto, la biblioteca del Condestable atesoraba una ingente cantidad de libros de materia histórica. Ahora bien, desde el punto de vista de su organización material, ocurre que los libros de una y otra modalidad tienen ubicaciones diferenciadas (salvo en el llamado camarín). La razón es fácil de comprender: el uso del verso en la épica sirve como criterio discriminador, que lo separa de la historia y lo emparenta con otras producciones también en metro, como la lírica o la dramática ${ }^{1}$. De esta manera, los libros que aquí nos interesan aparecen inventariados de manera concreta en los cajones 24 y 25, tanto bajo como alto, con excepción de la media docena que se guardaban en el camarín. Esos cuatro cajones atesoraban fundamentalmente una interesantísima colección de poesía y literatura dramática en lenguas vernáculas (español, portugués, francés, italiano y varios dialectos). La relación de poemas de tema heroico figura en el apéndice del trabajo, según el orden topográfico del inventario notarial.

\section{Poemas italianos y franceses}

No descubrimos nada al decir que es en la Italia del Renacimiento donde la poesía heroica conoce un desarrollo más temprano y sostenido, tanto el aspecto de la creación como en el de la reflexión teórica. Esta tuvo uno de sus puntos centrales de debate en la distinción entre los poemas heroico-caballerescos al estilo del Orlando furioso (romanzi) y los poemas épicos strictu sensu (Josa, 2002; Esteve, 2010; Javitch, 2010). La cuestión no pasa desapercibida en la biblioteca del Condestable, ya que encontramos en ella algunos títulos representativos de la misma, como los inexcusables de Giovan Battista Giraldi Cinzio ( Discorso intorno al comporre de $i$ Romanzi, delle Comedie, delle Tragedie, et altre maniere di Poesie, 1554) y de Torquato Tasso (Discorsi del poema heroico, 1587), pasando por Gli heroici de Giovanni Battista Pigna (1561), pionero en la propuesta de una épica con fundamento en la historia contemporánea. Con todo, en la disposición de la biblioteca ocurre lo previsible: no se hace distinción entre una y otra suerte de poesía heroica; pese a lo cual la tomaremos como criterio a la hora de presentar los datos. 
13 La abundancia de títulos italianos es muy patente. En el caso de los romanzi, destaca la presencia del Orlando ariostesco, acompañado de otros títulos relacionados con esa misma materia². Por motivos obvios, no podía faltar L'Amadigi de Bernardo Tasso (1560), máxime teniendo en cuenta que el Amadís es uno de los escasos libros de caballerías que atesora la biblioteca, acaso como recuerdo de una lectura juvenil del noble. Y junto a estos, otros títulos, como el Libro de la regina Anchroia che narra li mirandi fatti darme de li paladini de Franza, anterior a 1500; I quattro primi canti del Lancilotto (1580), del prolífico Erasmo di Valvasone, autor muy representado en la biblioteca; o Il fido amante (1582), de Curzio Gonzaga.

Las preferencias del Condestable apuntaban, sin embargo, en otras direcciones que él debía juzgar más acordes con su rango: la épica de inspiración histórica y la de carácter sacro. En lo que respecta a la primera, el elenco de títulos italianos es bastante amplio y coherente. Así, encontramos la obra seminal (y más bien fracasada) de Gian Giorgio Trissino La Italia liberata dai Goti (1547-1548), de la que Velasco solo poseía la segunda entrega, esto es, los cantos X a XX), flanqueada, eso sí, por la ulterior revisión del tema por parte de Gabriello Chiabrera, Delle guerre de' Goti (1582); y naturalmente, no falta la Gerusalemme de Torquato Tasso, tanto en la versión liberata (1575) como en la conquistata (1593). Particular interés tiene, desde nuestro punto de vista, un pequeño grupo de poemas que comparten la inspiración en la historia contemporánea, concretamente en sucesos relacionada con la amenaza que representaba el imperio otomano. Así, el célebre sitio de Malta por los turcos en 1565 está en el origen de La Malteide (1596), obra del veronés Giovanni Fratta; la caída en manos otomanas de Giavarino (hoy Győr, en Hungría), en 1594, da pie a unas Stanze per l'vnione de' prencipi christiani scritte nella perdita di Giavarino (1595), publicadas a nombre de Ardito Accademico Risoluto (probablemente Agostino Michele); el abortado asalto naval de los turcos a Tarento (1594) es el marco del que se sirve Cataldo Antonio Mannarino en Glorie di guerrieri e d'amanti in nuova impresa nella città di Taranto succedute (1596), si bien es cierto que la narración se explaya luego en aventuras caballerescas. La confirmación del interés de Velasco por este tipo de literatura la tenemos en la existencia en su biblioteca del manuscrito de lo que seguramente es un poema de encargo acerca de la única campaña militar que dirigió (y con escaso éxito, por cierto), la de Fontaine-Française, por tierras de Borgoña, en 1595. Pues bien, el asunto dio para un poema que está dedicado al Condestable: el Trattato delle guerre di Francia et di Spagna in Octaua Rima, obra de un tal Giovanni Paolo Novarese, cuya copia se conserva actualmente en la Bancroft Library de Berkeley (California).

Por la relación de títulos ofrecida se habrá podido comprobar que una parte de esos poemas de tema histórico tocan asuntos que también están relacionados con la fe. Es una consecuencia lógica del clima contrarreformista en que se desenvuelve la poesía italiana de la época, que llevó a Torquato Tasso a considerar el componente religioso como imprescindible en el poema épico. En consonancia con estas ideas, se produce desde mediados del XVI un importante desarrollo de la épica de tema sacro, proceso que ha dejado abundantes huellas en la biblioteca del Condestable. Unas veces se trata de narraciones que tocan temas de la mitología cristiana, como es el caso de la Angeleida (1590) de Erasmo di Valvasone, sobre la lucha entre los ángeles buenos y los ángeles rebeldes; o de la historia sacra, como el poema Della croce racquistata (1605, primera versión), de Francesco Bracciolini, sobre el conocido episodio de la recuperación de la Vera Cruz por parte del emperador Heraclio. Pero la temática predominante fue la exaltación de los santos y otras figuras de la fe, como bien refleja la biblioteca del 
Condestable. En particular, abundan los poemas relacionados con la Sagrada Familia: Lodovico Dolce, La vita di Giuseppe, discritta in ottava rima (1556), Orazio Guarguanti, Eccellenze di Maria Vergine in ottava rima (1586); Capoleone Ghelfucci, Il Rosario della Madonna Poema Eroico (1600), del que constan dos ejemplares, y que en sus 34 cantos narra las vidas de María y su Hijo; en fin, Lucrezia Marinelli, La vita di Maria Vergine Imperatrice dell'universo descritta in prosa \& in ottava rima (1602). Con la misma materia guarda relación la obra de Luigi Tansillo, Le lagrime di San Pietro (1585), en trece llantos, pero incompleta, y que tuvo bastante difusión en España ${ }^{3}$. Junto a estos, encontramos otros dedicados a santos, como María Magdalena, protagonista tanto del poemita de Erasmo di Valvasone, Lagrime di santa Maria Maddalena (1586), como del más extenso de Paolo Silvio, La Madalena penitente poema heroico (1602). Asimismo figuran en la biblioteca La trionfatrice Cecilia vergine e martire romana (1594), del dominico Sebastiano Castelletti; y La Colomba sacra poema heroico (1595), de Lucrezia Marinelli, sobre la mártir y santa del mismo nombre 4 franceses, con la diferencia de que en este caso el número de libros es muy reducido. Así, encontramos el poema de inspiración histórico-legendaria La Franciade, inacabada, de Pierre de Ronsard (1572); la materia del romanzo caballeresco en las imitaciones de fragmentos del Orlando furioso incluidas en las Euvres de Philippe Desportes (1572); y, por último, un poema enciclopédico con rasgos de épica sacra en La semaine ou Création du Monde (1578-1579), de Guillaume de Salluste du Bartas, de la que Velasco poseía tres ejemplares, uno en francés y dos en italiano.

\section{Poemas españoles y portugueses}

Las particulares circunstancias históricas de las dos naciones ibéricas, en su papel de punta de lanza de la expansión colonial europea, favoreció una particular concepción del género que María José Vega ha resumido acertadamente con los términos épica «del presente», $\mathrm{y}$ «de la verdad» (2010: 107):

La idea de la épica en la cultura quinientista hispánica podría describirse, aunque no exclusivamente, a partir de los lugares más reescritos de prólogos y dedicatorias. Quizá el más recurrente es el que quiere que la épica sea una versión mejorada y exaltada de la historia, más memorable y enfática. $Y$, sobre todo, el que quiere que la épica sea el instrumento para edificar la memoria política de las naciones presentes y para apuntalar desde la historia poética la legitimidad de una empresa política y religiosa que se representa como colectiva (2010: 106-107).

Siendo esto así, la imagen del género que se desprende de la biblioteca del Condestable muestra un sesgo algo particular. Como muestra, un dato: no constan en ella ninguna de las varias caroleas que se escribieron exaltando la figura del Emperador ${ }^{5}$. En lo relativo a materia histórica o histórico-legendaria, la colección mira más bien hacia el pasado medieval. Más allá incluso se remonta la Primera parte de la Historia de Sagunto, Numancia y Carthago (1589), de Lorenzo de Zamora, también conocida como La Saguntina ${ }^{6}$. Pero, insistimos, son los temas medievales los más representados, sea en el recuerdo de algunos héroes del panteón nacional, caso de Don Pelayo (Alonso López Pinciano, El Pelayo, 1605) o del Cid (Diego Jiménez Ayllón, Los famosos y heroicos hechos del invencible y esforçado Cauallero... el Cid Ruy Díaz de Bivar, 1579) ${ }^{7}$; sea en la memoria de algunas batallas decisivas, como la de Roncesvalles, tan sujeta a la recreación legendaria en nuestra letras: Francisco Garrido de Villena, El verdadero sucesso de la famosa batalla de Roncesvalles, con la muerte de los doze pares de Francia (1555); o la de las Navas: Cristóbal de Mesa $^{8}$, Las Navas de Tolosa. 
Poema heroico (1594). Una preferencia por lo medieval que en el caso de algunos de los autores podría explicarse como fidelidad a la idea tassiana de que la épica debe tratar una materia histórica ni demasiado remota ni demasiado cercana, pero que en el caso del propietario de los libros la interpretamos más bien como reflejo de su mentalidad goticista (García Cárcel, 2004).

La historia más reciente proporciona, por su parte, un número de títulos más exiguo, pese a la abundante producción contemporánea ${ }^{9}$. Para empezar, tenemos ahí un poema que se sitúa en los prolegómenos del género en su etapa renacentista: la Historia parthenopea (1516) de Alonso Hernández, centrada en la figura del Gran Capitán y todavía escrita en el verso de arte mayor cuatrocentista. Y casi para terminar, la Tercera parte de la Araucana (1589), de Alonso de Ercilla, título -incompleto, además: faltan las dos partes previasque de manera sorprendente es el único testimonio de la producción española de tema colonial. Para encontrar otros, tenemos que mirar hacia la épica portuguesa, representada en la biblioteca de Velasco por sus dos títulos señeros: Os Lusíadas (1572) de Luís de Camões, en su lengua original y en dos ediciones distintas, y Sucesso do segundo cerco de Diu (1574), de Jerónimo Corte-Real, pero en la traslación castellana de Pedro de Padilla $(1597)^{10}$.

La épica sacra, por su parte, vuelve a ocupar un lugar destacado en la biblioteca. La muestra más temprana es Los Christiados de Hyeronimo Vida, traducida del latín al castellano por Juan Martín Cordero (1554); en la misma línea temática se sitúa la obra de Juan Coloma, Década de la Passión de Nuestro Redemptor Iesu Christo, con otra obra intitulada Cántico de su gloriosa Resurrección (1576). La temática hagiográfica está representada por dos obras del franciscano Gabriel Mata (O.F.M.), que era natural de Medina de Pomar, villa del señorío de Velasco: Segundo volumen del Cavallero Asisio (1589), con las vidas de cinco santos de la orden, uno de los cuales es Santa Clara, bajo cuya advocación habían fundado los Velasco un monasterio en la citada localidad burgalesa; y Vida, muerte y milagros de S. Diego de Alcalá de Henares, en octava rima (1589), santo cuya canonización acababa de producirse en 1588, por Sixto V. Por último, encontramos las dos versiones del Monserrate (1588 y 1602) de Cristóbal de Virués, otro autor que parece haber estado próximo al Condestable (Montero, González, Rueda \& Alonso, 2014: 279).

\section{Conclusiones}

21 El capítulo de la épica vernácula reproduce a pequeña escala el diagrama de las letras contemporáneas en la biblioteca de Velasco. Constatamos así el predominio de la producción italiana (incluyendo alguna muestra dialectal), seguida de la española, con presencia más bien testimonial - pero con títulos bien elegidos- de la francesa y de la portuguesa. Si de lo cuantitativo pasamos a lo cualitativo, se observa que es el dominio italiano e que goza de la representación más coherente y completa de las diversas tendencias del género, ya que abarca no solo las varias modalidades del mismo, sino también tres de los títulos más representativos de los debates teóricos sobre su naturaleza. Todo esto viene a confirmar, de un lado, el sesgo italianizante de la colección del Condestable (López Vidriero, 2008), y de otro su condición de connaisseur en lo que a las letras italianas se refiere.

En el caso español, y siempre contando con los datos que nos proporcionan los diferentes inventarios, la colección resulta, en cambio, algo desequilibrada e incompleta. De los 
cuatro títulos que Cervantes, al hacer el escrutinio de los libros de Don Quijote, destaca acertadamente como los principales del género, esto es, Las lágrimas de Angélica, La Araucana, La Austríada y El Monserrate, solo encontramos dos en la biblioteca de Velasco, el segundo (pero incompleto) y el cuarto, eso sí, en sus dos versiones. La mínima presencia de la épica española de tema colonial, y en general de la épica de tema contemporáneo, da más realce todavía al gusto de Velasco por las narraciones tocantes a los orígenes medievales de la nación española (aunque con alguna ausencia llamativa, como la de La restauración de España, de Cristóbal de Mesa). Interés que, sumado al que recibe la épica sacra, configura una mentalidad en la que nacionalismo goticista y fe se refuerzan mutuamente.

Es indudable que una biblioteca como la de Velasco sirve en buena medida para proyectar la imagen que el poderoso quiere dar de sí. Pero no son pocas las noticias contemporáneas que hablan del Condestable como un lector infatigable (Montero, González, Rueda \& Alonso, 2014). Resulta difícil, en cualquier caso, saber qué lugar específico le corresponde a la épica vernácula en esa dedicación lectora. La ubicación de algunos de los títulos en el llamado camarín de la biblioteca parece indicar una mayor cercanía y no solo física, pero tampoco puede descartarse que se trate de una localización coyuntural o pasajera. El hecho es que si ponemos la atención en la media docena de títulos que ahí se encontraban, se nos revela una especie de microcosmos marcado por los intereses ideológicos antes apuntados: en primer lugar, la fe y la historia sagrada (Bracciolini, Ghelfucci) junto los orígenes de la nación española (Mesa, López Pinciano); pero sin que falte el gusto por la erudición antigua (Estacio traducido por Valvasone) o la afición por lo histórico-caballeresco contemporáneo (Mannarino). La obra de este último, en lo que tiene de celebrativo y hasta autobiográfico - pues el propio autor estuvo implicado en el hecho de armas que sirve de marco al poema- podría traslucir el deseo por parte de Velasco de verse celebrado en un poema épico, algo que se cumplió de manera más bien mediocre en la obra manuscrita de Giovanni Paolo Novarese. Y es que la biografía de Velasco no se prestaba tanto al relato épico como al encomio de su singular afición por los libros, de la que su biblioteca se erige en un duradero monumento.

\section{BIBLIOGRAFÍA}

ANDRÉs Gregorio de (1972), «Descripción sumaria de las colecciones de códices griegos del siglo XVI», Estudios clásicos, 66-67, 219-228.

Bøuf Estelle (2007), La bibliothèque parisienne de Gabriel Naudé en 1630 : les lectures d'un libertin érudit, Genève: Droz.

CACHO CASAL Rodrigo (dir.) (2012), La poesía épica en el Siglo de Oro, Criticón, 115.

CHEVAliER Maxime (1966), L'Arioste en Espagne (1530-1650). Recherches sur l'influence du « Roland furieux ", Bordeaux: Féret \& Fils.

CHEVALIER Maxime (1976), Lectura y lectores en la España del siglo XVI y XVII, Madrid: Turner. 
COFIÑo FERnÁNDEZ Isabel \& ESCUdERo SÁNCHEZ María Eugenia (2008), «Nuevas aportaciones al coleccionismo español de la Edad Moderna: la galería de retratos de la familia Velasco», BSAA Arte: Boletín del Seminario de Estudios de Arte, 74(2), 151-184.

DADSON Trevor J. (1998), Libros, lectores y lecturas: estudios sobre bibliotecas particulares españolas del Siglo de Oro, Madrid: Arco/Libros.

ESTEVE Cesc (2010), «Una teoría incompleta: la idea de la poesía épica en las artes poéticas italianas del siglo XVI», M. J. Vega \& L. Vila (dir.), La teoría de la épica en el siglo XVI: (España, Francia, Italia y Portugal) (63-101), Vigo: Editorial Academia del Hispanismo.

Fenucci Fabrizio, SimonetTA Marcello (2007), «The Studiolo in the 'Cube': A Visual Guide», Federico de Montefeltro and his library (88-99), Milano: Y. Press; Roma: Biblioteca Apostolica Vaticana.

FERNÁNDEZ PomAR José María (1967), «Manuscritos del VI condestable de Castilla en la Biblioteca Nacional», Helmantica, 18, 89-108.

GARCía CÁRCEl Ricardo (dir.) (2004), La construcción de las historias de España, Madrid: Marcial Pons; Fundación Carolina, Centro de Estudios Hispánicos e Iberoamericanos.

JosA Stefano (2002), La fondazione di un genere. Il poema eroico tra Ariosto e Tasso, Roma: Carocci.

JAVITch Daniel (2010), «El descrédito y la atracción del romanzo caballeresco en la teoría (y en la práctica) épica italiana del siglo XVI», M. J. Vega \& L. Vila (dir.), La teoría de la épica en el siglo XVI (España, Francia, Italia y Portugal) (221-239), Vigo: Editorial Academia del Hispanismo.

KOERING Jérémie (2013), Le prince en représentation : histoire des décors du palais ducal de Mantoue au XVI ${ }^{e}$ siècle, Arles: Actes Sud.

LóPEZ DE MENDIZORROZ Fermín (1625), Observaciones de la vida del condestable Ivan Fernandez de Velasco y Cifra de sus dictamenes, Vigeven: Iuan Baptista Malatesta Impresor Real.

LÓPEZ TORRIJOS Rosa (1998), «Humanismo y tradición: la decoración de la Real Biblioteca», Felipe II y el arte de su tiempo (119-132), [Madrid]: Fundación Argentaria, UAM-Visor.

LóPEZ-VIDRIERo ABELLo María Luisa (2008), «Encomio y gloria: brillo imperial del Milanesado en los libros italianos de las colecciones de Frías y Gondomar», A. Gloria Egido Martínez \& J. E. Laplana Gil (coord.), Mecenazgo y Humanidades en tiempos de Lastanosa: Homenaje a Domingo Ynduráin (303-324), Zaragoza: Instituto de Estudios Altoaragoneses; Institución Fernando el Católico.

Matilla Tascón Antonio (1983), Testamentos de 43 personajes del Madrid de los Austrias, Madrid: Instituto de Estudios Madrileños.

Montero Juan, González SÁnchez Carlos Alberto, Rueda Ramírez Pedro \& Alonso Moral Roberto (2014), De todos los ingenios los mejores. El Condestable Juan Fernández de Velasco y Tovar, V Duque de Frías (c. 1550-1613), Sevilla: Real Maestranza de Caballería.

MirTo Alfonso (1990), La Biblioteca del Cardinal Leopoldo de Medici: catalogo, Firenze: Olschki.

PRIETO BERnABÉ José Manuel (2004), Lectura y lectores: la cultura del impreso en el Madrid del Siglo de Oro (1550-1650), Mérida: Editora Regional de Extremadura.

TORREGo CASADO Almudena (2011), Una biblioteca nobiliaria madrileña del siglo XVII: Don Jerónimo de Eguía y Eguía, primer marqués de Narros, Madrid: Universidad Complutense.

VEGA María José (2010), «Idea de la épica en la España del Quinientos», M. J. Vega \& L. Vila (dir.), La teoría de la épica en el siglo XVI (España, Francia, Italia y Portugal) (103-135), Vigo: Editorial Academia del Hispanismo. 
VíLCHEZ DíAz Alfredo (1986), Autores y anónimos españoles en los índices inquisitoriales, Madrid: Universidad Complutense.

\section{ANEXOS}

\section{Apéndice}

Se recogen aquí los poemas de épica vernácula que hemos podido identificar como tales en los dos inventarios que existen de la librería del Condestable (AHPM, leg. 24850, e Index auctorum, BNE, ms. 7840). Los poemas aparecen en el orden topográfico del inventario notarial (1608), con la numeración que tienen actualmente en nuestra edición en curso del citado documento. Siempre que ha sido posible, indicamos aquí la edición concreta que poseía el Condestable. Para ello hemos localizado en el Index auctorum - que ofrece información precisa del pie de imprenta- los títulos recogidos en el inventario notarial; ocasionalmente, los datos del inventario han sido suficientes para la identificación de algunos libros que no figuran en el Index.

\section{Cajón xxiiij bajo}

1709. Vida, Marco Girolamo. Los Christiados de Hierónimo Vida ... traducidos en verso castellano por Iuan Martín Cordero. Amberes, Martín Nucio, 1554. $8^{\circ}$.

1710. Trissino, Gian Giorgio. La Italia liberata da Gotthi.

Es difícil decidir si la edición reseñada es la primera, que contiene los libros I a IX (Roma, per Valerio e Luigi Dorici, 1547; colofón: Venezia, Tolomeo Ianiculo da Bressa, 1548); la continuación, con los libros X a XXVII (Venezia, Tolomeo Ianiculo da Bressa, 1548); o si se trataba de un volumen facticio con ambas. Las dos in $8^{\circ}$.

1714. Corte Real, Jerónimo. La verdadera historia y admirable suceso del segundo cerco de Diu ... traducido en lengua castellana por Fray Pedro de Padilla... Alcalá de Henares, Iuan Gracián, 1597. $8^{\circ}$.

1716. [Manuscrito] Hermosilla, Francisco de (O.S.B.). Primera parte del valeroso Zayde en octava rima. [Index auctorum, f. 79r].

Actualmente, es el ms. 11.247 de la Biblioteca Nacional: Primera parte del valeroso Zayde compuesta por ... natural de San Martín de Valdeiglesias y capellán del exército de Su Magestad [Felipe II].

1717. Virués, Cristóbal de. El Monserrate segundo del capitán... Milán, Gratiadio Ferioli, 1602. $8^{\circ}$.

1721. Garrido de Villena, Francisco. El verdadero suceso de la famosa batalla de Roncesvalles, con la muerte de los doce pares de Francia ... por ... cauallero de Valencia.

En una de sus dos ediciones: Valencia, Ioan Mey Flandro, 1555; Toledo, Iuan Rodríguez, 1583. Las dos in $4^{\circ}$.

1723. Jiménez Ayllón, Diego. Los famosos y heroicos hechos del invencible y esforzado Caballero, honra y flor de las Españas, el Cid Ruy Díaz de Bivar... Alcalá de Henares, Iuan Íñiguez de Lequerica, 1579 (1580). $4^{\circ}$. 
1726. Mata, Gabriel de (O.F.M.). Segundo volumen del Caballero Asisio ... en las gloriosas vidas de cinco famosos santos de su orden, S. Clara, S. Antonio de Padua, S. Buenaventura, S. Luis Obispo de Tolosa, y San Bernardino. Logroño, Mathías Mares, 1589. $4^{\circ}$.

1728. Camões, Luis de. Os Lusiadas. Lisboa, Antonio Gõçaluez, 1572. $4^{\circ}$. Véase más abajo n. ${ }^{\circ}$ 1750.

1732. Coloma, Juan. Décadas de la Pasión de Nuestro Redentor Iesu Christo, con otra obra intitulada Cántico de su gloriosa Resurrección. Caller [Cagliari], Viçencio Sembenino, 1576. $8^{\circ}$. 1733. Mata, Gabriel de (O.F.M.). Vida, muerte y milagros de S. Diego de Alcalá en octaua rima ... Con las Hieroglíphicas y versos que en alabanza del Santo se hicieron en Alcalá para su procesión y fiesta. Alcalá de Henares, Iuan Gracián, 1589. $8^{\circ}$.

1737. Zamora, Lorenzo de (O. Cist.). Primera parte de la Historia de Sagunto, Numancia y Cartago. Alcalá de Henares, Iuan Íñíguez de Lequerica, 1589. $4^{\circ}$.

1739. Arbolanche, Jerónimo. Los nueve libros de las Habidas. Zaragoza, Iuan Millán, 1566. $8^{\circ}$. 1750. Camões, Luis de. Os Lusiadas.

Edición lisboeta que no es posible identificar con precisión.

1756. Lucano, Marco Anneo. Lucano traducido de verso latino en prosa castellana por Martín Laso de Oropesa. Burgos, Felipe de Iunta, 1588 (1578). Fol.

Obra en prosa.

1757. Hernández, Alonso. Historia parthenopea. Roma, Stephano Guilleri de lo Reño, 1516. Fol.

1761. Ercilla, Alonso de. Tercera parte de la Araucana. Madrid, Pedro Madrigal, 1589. $4^{\circ}$.

1764. [Manuscrito] El Pelayo.

No sabemos si tiene relación con la obra de Alonso López Pinciano que luego aparece impresa (n. $\left.{ }^{\circ} 3134\right)$.

1769. [Manuscrito] Suceso de la batalla naval.

No es seguro que se trate de un poema.

1781 y 1782. Desportes, Philippe. Les CEuvres.

Seguramente se trata de dos ejemplares de la ed. Amberes, Arnould Coninx, 1596. $12^{\circ}$.

1783. Ronsard, Pierre de. Les quatre premiers livres de la Franciade. Lyon, Thomas Soubron, 1592. $12^{\circ}$.

1784. Du Bartas, Guillaume de Saluste. La Sepmaine ou Création du monde. [¿Ginebra?], Iacques Chouet, 1593. $12^{\circ}$.

1788. Du Bartas, Guillaume de Saluste. La Diuina settimana; cioè, I sette giorni della creazione del mondo, del signor Guglielmo di Salusto signor di Bartas, tradotta di rima francese in verso sciolto italiano dal sig. Ferrante Guisone.

Hay cinco ediciones venecianas del libro, siempre en la imprenta de Gio. Battista Ciotti, entre 1593 y 1601.

\section{Cajón xxiiij alto}

1802. Valvasone, Erasmo di. Angeleida. Venecia, Gio. Battista Sommasco, 1590. $4^{\circ}$. 
1815. Chiabrera, Gabriello. Italia liberata, overo delle guerre de' Goti. Nápoles, Henrico Bacco, 1604. $4^{\circ}$.

\section{Cajón bajo xxv}

1868. Dolce, Lodovico. La vita di Giuseppe. Venecia, Gabriel Giolito de’ Ferrari, 1561. $4^{\circ}$. 1872. Pigna, Giovanni Battista. Gli heroici. Venecia, Gabriel Giolito de' Ferrari, 1561. $4^{\circ}$. 1875. Marinelli, Lucrezia. La colomba sacra. Venecia, Gio. Battista Ciotti, 1595. $4^{\circ}$. 1876. Valvasone, Erasmo di. I quattro primi canti del Lancilotto. Venecia, Domenico e Giovanni Battista Guerra, 1580. $4^{\circ}$. 1877. Castelletti, Sebastiano (O.S.D.). La trionfatrice Cecilia vergine, e martire romana. Florencia, Filippo Giunti, 1594. $4^{\circ}$.

1878. Fratta, Giovanni. La Malteide. Venecia, Marc'Antonio Zaltieri, 1596. $4^{\circ}$.

1891. Virgilio Marón, Publio. L'Eneide ... del commendatore Annibal Caro. Venecia, Bernardo Giunti, 1592. $4^{\circ}$.

1892. Gonzaga, Curzio. Il fido amante. Mantua, Giacomo Ruffinello, 1582. $4^{\circ}$.

1893. Dolce, Lodovico. L'Achille et l'Enea. Venecia, Gabriel Giolito de' Ferrari, 1572. $4^{\circ}$. 1894. Ardito Accademico Risoluto. Stanze per l'vnione de' prencipi christiani scritte nella perdita di Giauarino. Bérgamo, Comin Ventura, 1595. $4^{\circ}$.

1941. Udine, Ercole. La Psiche. Venecia, Gio. Battista Ciotti, 1599. $8^{\circ}$.

1942. Tansillo, Luigi. Le lagrime di San Pietro ... Con le Lagrime della Maddalena del signor Erasmo da Valvasone ... et aggiuntovi l'eccellenze della gloriosa Vergine Maria, del signor Horatio Guargante da Soncino. Venecia, Gio. Battista Bonfadino, 1598. $8^{\circ}$.

\section{Cajón alto $x x v$}

1999. [Index auctorum, f. 105r] Udine, Ercole. L'Eneide di Virgilio ridotta in ottava rima. Venecia, Gio. Battista Ciotti, 1592. $4^{\circ}$.

2000. Libro de la regina Anchroia che narra li mirandi fatti darme de li paladini de Franza. No es posible identificar la edición concreta.

2004. Virgilio Marón, Publio. L'opere di Vergilio ... da diversi eccellentissimi auttori tradotte in versi sciolti ... raccolte da m. Lodouico Domenichi.

No es posible identificar la edición concreta.

2005. Ghelfucci, Capoleone. Il Rosario della Madonna. Venecia, Nicolo Polo, 1600. $4^{\circ}$. Otra edición en n. ${ }^{\circ} 3187$.

2009. [Index auctorum, f. 92v] Cardello, Giovanni Paolo. Trattato delle guerre di Francia et Spagna... In ottava rima.

El poema, que está dedicado al Condestable, se conserva actualmente en la Colección Fernán Núñez de la Bancroft Library (California).

2011. Orlandi, Giovanni. Compendio de l'historie citate da Lodouico Ariosto nel trigesimo tertio canto di Orlando Furioso. Roma, Valerio Dorico, 1555. $4^{\circ}$.

Obra en prosa. 
2012. Tasso, Torquato. Discorsi del poema heroico. Nápoles, Stigliola [¿1594?]. $4^{\circ}$.

Obra en prosa.

2017. Tasso, Torquato. Discorsi ... dell'Arte Poetica; et in particolare del Poema Heroico. Venecia, Giulio Vassalini, 1587. $4^{\circ}$.

2018. Tasso, Bernardo. L'Amadigi. Venecia, Fabio, \& Agostino Zoppini fratelli, 1583. $4^{\circ}$.

2023. Tasso, Torquato. Il Goffredo overo Gierusalemme liberata...; et $i$ Cinque canti del sig.

Camillo Camilli.

No es posible identificar la edición concreta.

2025. Tasso, Torquato. Della Gerusalemme Conquistata ... libri XXIV.

No es posible identificar la edición concreta.

2029. Ariosto, Ludovico. Orlando furioso. Venecia, Nicolo Misserino, 1596. $8^{\circ}$.

\section{Camarín}

2898. Bracciolini, Francesco. Della croce racquistata ... libri 15. París, Renato Ruelle, 1605. $8^{\circ}$. 3132. Mesa, Cristóbal de. Las Navas de Tolosa. Madrid, viuda de P. Madrigal, 1594. $8^{\circ}$.

3134. López Pinciano, Alonso. El Pelayo. Madrid, Luis Sánchez, 1605. $8^{\circ}$.

3185. Mannarino, Cataldo Antonio. Glorie di guerrieri e d'amanti in nuova impresa nella citta di Taranto succedute. Nápoles, Gio. Giac. Carlino et Antonio Pace, 1596. $4^{\circ}$.

3187. Ghelfucci, Capoleone. Il Rosario della Madonna. Turín, Gio. Domenico Tarino, 1602. $4^{\circ}$. Otra edición en n. ${ }^{\circ} 2005$.

3197. Estacio, Publio Papinio. La Thebaide ... ridotta dal sig. Erasmo di Valvasone in ottava rima. Venecia, Francesco de' Franceschi, 1570. $4^{\circ}$.

\section{Relación de autores y traductores:}

Arbolanche, Jerónimo, 1739.

Ardito Accademico Risoluto, 1894.

Ariosto, Ludovico, 2029.

Bracciolini, Francesco, 2898.

Camões, Luis de, 1728, 1750.

Cardello, Giovanni Paolo, 2009.

Caro, Annibale, 1891.

Castelletti, Sebastiano (O.S.D.), 1877.

Chiabrera, Gabriello, 1815.

Coloma, Juan, 1732.

Corte Real, Jerónimo, 1714.

Desportes, Philippe, 1781, 1782.

Dolce, Lodovico, 1868, 1893.

Du Bartas, Guillaume de Saluste, 1784, 1788.

Ercilla, Alonso de ,1761.

Estacio, 3197.

Fratta, Giovanni, 1878.

Garrido de Villena, Francisco, 1721. 
Ghelfucci, Capoleone, 2005, 3187.

Gonzaga, Curzio, 1892.

Guarguanti, Orazio, 1942.

Hermosilla, Francisco de (O.S.B.), 1716.

Hernández, Alonso, 1757.

Jiménez Ayllón, Diego, 1723.

Laso de Oropesa, Martín, 1756.

López Pinciano, Alonso, 3134.

Lucano, 1756.

Marinelli, Lucrezia, 1875.

Mannarino, Cataldo Antonio, 3185.

Martín Cordero, Juan, 1709.

Mata, Gabriel de (O.F.M.), 1726, 1733.

Mesa, Cristóbal de, 3132.

Orlandi, Giovanni, 2011.

Padilla, Pedro de (O.C.), 1714.

Pigna, Giovanni Battista, 1872.

Ronsard, Pierre de, 1783.

Tansillo, Luigi, 1942.

Tasso, Bernardo, 2018.

Tasso, Torquato, 2012, 2017, 2023, 2025.

Trissino, Gian Giorgio, 1710.

Udine, Ercole, 1941, 1999.

Valvasone, Erasmo di, 1802, 1876, 1942, 3197.

Vida, Marco Girolamo, 1709.

Virgilio, 1891, 1999, 2004.

Virués, Cristóbal de, 1717.

Zamora, Lorenzo de (0. Cist.), 1737.

\section{NOTAS}

1. Nótese, en cambio, que no ocurre lo mismo en el caso de las obras (no muchas, es cierto) de prosa de ficción, cuyos títulos aparecen dispersos entre los de historia.

2. Se trata de glosas o comentarios como el de Giovanni Orlandi, Compendio de l'historie citate da Lodouico Ariosto nel trigesimo tertio canto di Orlando Furioso da lui composto (1555), o el de Laura Terracina, Discorso sopra il principio di tutti i canti d'Orlando Furioso (1559); secuelas, como la de Giovanni Battista Pescatore La morte di Ruggiero con la vendetta, et nascimento di Ruggiero suo figlio detto Ruggino (1546); o incluso versiones dialectales (Rime di Magagno Menonce Begotto in lingua rustica padouana con una tradottione del pro canto di Ariosto, 1564).

3. Nótese que en la edición que poseía el Condestable (Venezia, Gio. Battista Bonfadino, 1598) la obra iba acompañada de otros dos títulos, el ya citado de Orazio Guarguanti y el que se cita a continuación de Erasmo di Valvasone sobre la Magdalena.

4. La relación de poemas italianos puede incrementarse con algunas traducciones de clásicos: la Eneida de Virgilio, de la que el Condestable poseía tanto la traslación de Annibal Caro (1581) como la de Ercole Udine (¿1592?); o la Tebaida de Estacio, en la versión de Erasmo di Valvasone (1570). También puede añadirse el poema de tema mitográfico La Psiche (1599), de Ercole Udine. 
5. Compárese con el resumen que hace Vega (2010: 126-127) de las lecturas épicas de Alonso de Osorio, VII marqués de Astorga, en el que se aprecia una colección más numerosa de autores castellanos.

6. Con la historia antigua guarda relación asimismo el Lucano traduzido de verso latino en prosa castellana por Martín Laso de Oropesa (1588). Es interesante señalar que el libro se colocó entre los poéticos, seguramente en atención a la naturaleza de la obra literaria trasladada.

7. En el caso del caudillo astur, la biblioteca albergaba, además, una «Historia de Don Pelayo. Scripta de mano. In fol.» (Index auctorum, f. 108r). Su paradero actual nos es desconocido, por lo que nada podemos conjeturar sobre su contenido y posible relación con el poema impreso del mismo título. Lo mismo ocurre con otro ms. del cajón xxiv bajo: Succeso de la Vatalla naual.

8. Mesa fue un autor próximo al Condestable (Montero, González, Rueda \& Alonso, 2014: 279). Además del citado, es autor de otros dos poemas épicos: La restauración de España (1607) y El patrón de España (1612), este último sobre un tema caro al Condestable: la venida y predicación del apóstol Santiago en la Península Ibérica.

9. El dato es tanto más llamativo cuanto que sabemos que Velasco tuvo relación con algunos autores de poemas con esa temática (Montero, González, Rueda \& Alonso, 2014: 279), pero que no constan en su biblioteca, caso de Juan Rufo y La Austríada (1584), o Gabriel Lobo Lasso de la Vega y la Primera parte de Cortés valeroso o La Mexicana (1588, con versión revisada en 1594).

10. Todavía en materia contemporánea, podemos añadir, con reservas, este otro título: Primera parte del valeroso Zayde, obra del capellán militar fray Francisco de Hermosilla (O.S.B.), que Velasco poseía en un ms. que hoy se conserva en la Biblioteca Nacional de España (ms. 11247) y que podría ser copia de una edición milanesa desconocida de h. 1595. Pese al título, parece que trata de las guerras de los españoles contra los franceses en Saboya (Chevalier, 1966: 342).

\section{RESÚMENES}

Juan Fernández de Velasco (c. 1550-1613), V Duque de Frías, estuvo al servicio de Felipe II y Felipe III en tareas diplomáticas y como gobernador de Milán en dos ocasiones (1592-1600 y 1610-1612). A lo largo de su vida reunió una exquisita biblioteca que, entre otras muchas materias, albergaba una riquísima colección de textos poéticos en lenguas vernáculas. En el caso de la épica, predominaba la producción italiana (incluyendo alguna muestra dialectal), seguida de la española, sin que faltasen los títulos más significativos de la francesa y de la portuguesa. En conjunto, se trata de una colección representativa de las diversas tendencias del género, aunque llama la atención la ausencia o escasa presencia de ciertas líneas de la producción española, como la colonial o la dedicada a la exaltación de la casa de Austria. Al final del artículo, se incluye un apéndice con la relación de las obras y autores que figuraban en la biblioteca.

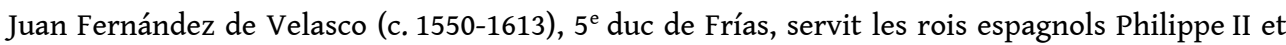
Philippe III dans des tâches diplomatiques et en tant que gouverneur de Milan entre 1592 et 1600 , puis de 1610 à 1612 . Il constitua au long de sa vie une riche bibliothèque qui réunissait, entre autres, une très vaste collection de poèmes en langues modernes. Pour ce qui est du genre épique, les textes italiens étaient les plus nombreux (y compris quelques productions dialectales), suivis de la production espagnole, sans oublier les œuvres françaises et portugaises les plus significatives. Il s'agit, dans l'ensemble, d'une collection représentative des différentes tendances du genre, mais il faut noter l'absence ou la rareté de certaines lignes de la production espagnole, 
comme par exemple les textes d'inspiration coloniale ou d'exaltation des Habsbourg. Une annexe finale inclut la liste des œuvres et des auteurs présents dans la bibliothèque.

This paper examines the private library of Juan Fernández de Velasco (c. 1550-1613), the fifth Duke of Frías, who served Felipe II and Felipe III on diplomatic missions and was twice Governor of the Duchy of Milan, in 1592-1600 and 1610-1612. During his life, Fernández de Velasco gathered an impressive collection of books containing a broad range of poetic works in vernacular languages. The epic poems in this collection are mainly in Italian (some in dialect) but there are also examples of Spanish works and the most important epic poems in French and Portuguese. In general, the collection offers a comprehensive account of the different schools in the epic genre, even though Spanish works are under-represented, especially those inspired by Spain's colonial conquests or written in praise of the house of Austria. The paper includes an appendix listing the works and authors comprising the collection.

\section{ÍNDICE}

Mots-clés: poésie épique de la Renaissance, bibliothèques privées, lectures nobles Keywords: the Renaissance epic, private libraries, books for the nobility

Palabras claves: épica renacentista, bibliotecas privadas, lecturas nobiliarias

\section{AUTORES}

\section{JUAN MONTERO}

Universidad de Sevilla

\section{PEDRO RUEDA RAMÍREZ}

Universitat de Barcelona 